\title{
Escultores del sonido: prácticas musicales creativas como elemento de transformación social
}

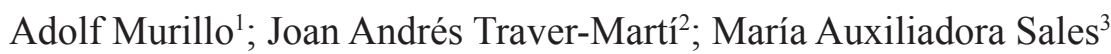

Recibido 17 Junio 2019 / Aceptado 4 Diciembre 2020

Resumen. El principal objetivo de esta investigación es mostrar de qué manera los usos de la tecnología planteados por músicos sin formación académica ("no músicos"), ofrecen un nuevo marco para la transformación social a través de sus prácticas musicales creativas. Como metodología de trabajo se utilizó la investigación etnográfica y la muestra se conformó a través de trece participantes con perfiles profesionales y trayectorias vitales de gran diversidad, con un patrón de coincidencia común: no tener formación musical académica (conservatorio). Como instrumentos y técnicas se emplearon las propias de esta metodología: las entrevistas individuales y grupales, el análisis documental de plataformas de intercambio del tipo netlabel o redes sociales y la observación participante en ensayos y conciertos. Los resultados revelaron que, al margen de lo académico e institucional, las prácticas creativas estudiadas generan auténticas redes de ciudadanos comprometidos con la construcción de la cultura contemporánea. Se destaca además, que este tipo prácticas a través de la tecnología aplicada a la creación musical permiten generar nuevos espacios para la creatividad colectiva, la colaboración y la difusión musical. Palabras Clave: creación sonora; tecnologías digitales; etnografía, arte ciudadano; creatividad; escucha; multidisciplinar; no músicos.

\section{[en] Sculptors of sound: creative musical practices as an element of social transformation}

Abstract. The primary goal of this research is to show how the use of technology proposed by musicians without academic training ("non-musicians"), offers a new framework for social transformation through their creative musical practices. Ethnographic research was carried out on a sample of 13 participants with highly diverse professional profiles and life trajectories, with only one thing in common: no academic musical training (conservatory). We used the methodology's instruments and techniques: individual and group interviews, documentary analysis of netlabel type exchange platforms or social networks and participant observation in rehearsals and concerts. The results of this research revealed that apart from the academic and institutional aspects, the creative practices studied generate authentic networks of citizens committed to the building of contemporary culture. It should also be noted that this type of practice through technology applied to musical creation allows new spaces to be created for collective creativity, collaboration and musical dissemination.

Keywords: sound creation; new technologies; ethnography; citizen art; creativity; listening; multidisciplinary; nonmusicians.

Sumario: 1. Introducción. 2. Materiales y Método. 3. Resultados. 3.1. Ver y escuchar la música: la liberación del creador a través de la revolución tecnológica. 3.2. El estudio doméstico como espacio de creación. 3.3. Compartir y construir desde las redes sociales: tecnología al servicio de la comunicación. 4. Discusiones y conclusiones. 5. Referencias Bibliográficas.

Cómo citar: Murillo, A.; Traver-Martí, J. A.; Sales, M. A. (2020). La formación de alumnado con discapacidad visual en el marco de los conservatorios de música en España, en Revista Electrónica Complutense de Investigación en Educación Musical, 17, 49-61

\footnotetext{
Universitat de València ( España)

E-mail: adolf.murillo@uv.es

Universitat Jaume I (España)

E-mail: jtraver@edu.uji.es

3 Universitat Jaume I (España))

E-mail: asales@edu.uji.es
} 


\section{Introducción}

Todavía hoy en día, por la fuerza de los discursos anti-tecnológicos que relacionan la tecnología con la deshumanización del arte, desde algunos sectores no se entiende que la tecnología ha estado presente en la música desde el principio de los tiempos (Eco, 2001). Asumido este hecho, hay que aceptar que cada cambio tecnológico ha supuesto un nuevo avance y ha afectado al arte musical en diferentes grados y maneras. Como afirma Delalande (2008, p.19), la democratización de las primeras tecnologías y sus usos creativos acabaron configurando nuevas formas de acceder y crear música, convirtiéndose en un "instrumento para componer".

Según Serra (2008), la popularización de las tecnologías de la información y la comunicación está provocando una revolución en la música. Los cambios son tan profundos que se puede hablar de una nueva cultura del sonido, puesto que permite alcanzar otro nivel de realidad sonora que es impensable desde el soporte escrito o notación. Desde este nuevo paradigma, la palabra "sonido" adquiere una dimensión que permite acercarse y diferenciar sutilezas que son utilizadas como materia primera para la construcción musical. En relación al nuevo paradigma Pardo (2014) habla de espacios donde nace y muere el sonido, de reverberaciones, de densidades, de ataques, de la granularidad del sonido, de calidad armónica que estimula y potencia la imaginación de aquel que se expone al sonido.

Los nuevos usos de las tecnologías aplicadas a la creación musical amateur han supuesto, como afirma Delalande (2004), que en los últimos años se multipliquen los compositores, favoreciendo una auténtica "crospolinación" de saberes (Cobo, 2016, p.82). Así mismo, este paradigma supone un contacto más "epidérmico" con el sonido y se convierte para los creadores amateurs en una actividad esencial, favoreciendo la creación de auténticas redes de colaboración.

Según Cobo y Moravec (2011), en un contexto laboral, entre el 10\% y 20\% de los aprendizajes se adquieren desde el contexto formal, el resto tienen su origen en incidencias como la interacción entre iguales, la observación o el ensayo-error. Gracias a la descentralización que han supuesto las tecnologías digitales respecto a los centros donde habitualmente se distribuía el conocimiento, se han hecho también más visibles y latentes las interacciones y estructuraciones de aprendizaje más horizontales, que se suelen dar en contextos educativos informales. Las diversas prácticas generadas en estos contextos conforman propuestas artísticas multialfabéticas, lo que intrínsecamente implica que los procesos de apropiación tecnológica sean diferentes entre sí y tomen caminos divergentes (Rostwall y Selander, 2008). Esto se ha hecho particularmente evidente en relación con las prácticas musicales y la ampliación de oportunidades para los creadores amateurs, facilitando el acceso y el aprendizaje de la música mediante contextos diferentes a los ofrecidos por las instituciones formales (O'Flynn 2006; Green, 2008; Feichas 2010).

La adopción de las tecnologías digitales en la vida cotidiana ha permitido ampliar los límites preestablecidos de aquello que tradicionalmente entendíamos como espacios de aprendizaje. Esta posibilidad permite crear laboratorios de aprendizaje, configurando redes o comunidades de creadores que contribuyen a hacer más significativa la adquisición y el intercambio de conocimientos.

Este tipo de comunidades conforman, según Lévy (2007), el intelecto colectivo. Según explica este mismo autor, es un tipo de sociedad anónima a la cual cada usuario aporta como capital su conocimiento, sus conversaciones, la capacidad de aprender y de enseñar. Lévy plantea que en el contexto virtual se enriquece esta idea del diálogo y la cooperación gracias al saber enriquecido por las individualidades de cada participante. Su tesis se sustenta en la idea que, si las tecnologías se orientan a ser mediadoras entre las inteligencias de los individuos que conforman la sociedad, podrían ver potenciadas sus capacidades creativas. Desde esta perspectiva, la sociedad puede verse como un sistema que logra un nivel superior de inteligencia colectiva que trasciende en el tiempo y el espacio a las inteligencias individuales que la conforman (Lévy, 2004).

El ordenador personal y la incorporación de los dispositivos móviles han permitido que muchos usuarios que antes eran simples espectadores pasen ahora a formar parte de comunidades de creadores y productores de música, alejándose de la visión de la ciudadanía como consumidora de bienes culturales y diluyendo la frontera entre lo profesional y amateur (Cobo, 2016).

Como señala Lévy (2007), uno de los primeros efectos de la digitalización es que el estudio de grabación esté al alcance del bolsillo de cualquier músico, que ahora tiene la capacidad de controlar personalmente todas las fases de producción de la música. En la línea de Márquez (2010), se trata de la lógica del Do-it-yourself del movimiento Punk traído a la era digital, donde converge con las características de la ética Hacker (Himanen, 2001). Esto quiere decir, compartir el saber bajo estructuras abiertas y horizontales que promueven la intercreatividad, el "artivismo" y la inteligencia colectiva, en beneficio de la comunidad (Cobo y Pardo, 2007, p.56 ).

Desde un punto de vista teórico, la inteligencia colectiva parte del principio que cada persona sabe algo sobre algo, por lo tanto, ninguna persona tiene el conocimiento absoluto (Sátiro, 2010). El ciberespacio, por sus propiedades -en torno a coordinación sin jerarquías que favorecen las sinergias de las inteligencias- es el ambiente perfecto para reconocer y movilizar los saberes de todas las personas (Lévy, 2004)

Este nuevo espacio conforma nuevos nodos de convergencia cultural donde se desarrolla un perfil de ciudadano artista que emerge más allá del ámbito académico e institucional, instaurando la era de los no músicos (Melero, 2012). Como señala Sevillano (2000, p.2), "para poder ser un no músico tiene que existir una herramienta o instrumento nuevo que lo permita, y en aquellos años -años 70s- acababan de aparecer los primeros sintetizadores". 
Realmente aquello que define a un no músico no es simplemente el uso del artefacto en cuestión, sino más bien, la actitud exploradora y empírica que provoca en cualquier persona el hecho de experimentar con los nuevos instrumentos. La época de los no músicos instaura, pues, una nueva relación con la existencia, es decir, con los paradigmas de pensamiento, las prescripciones estéticas, el rol del creador, de la obra, la escucha del músico y del arte en este mundo sonoro del s. XXI, que se enfrenta a numerosos estereotipos sujetos a estrechas categorías. Así pues, "el no músico de hoy, es muchas cosas: audioperformer, creador sonoro, paisajista sonoro, creador de redes, escultor de sonidos" (Barber y Palacios, 2009, p.113). Las formas de participación que surgen en estos contextos conforman unas nuevas cartografías culturales, al margen de las instituciones culturales y educativas, basadas en la colaboración con otros usuarios (una forma de educación P2P) a través del ensayo-error, la exploración y el bricolaje (Freire, 2010).

Esta investigación se basa en el estudio de las prácticas colaborativas centradas en una muestra de creadores sin formación musical académica que se mueven dentro del contexto informal, rico y permeable, de creación de nuevos escenarios culturales en redes "rizomáticas".

El objetivo de esta investigación es documentar las prácticas de creación sonora mediadas por la tecnología y que son utilizadas por no músicos ${ }^{4} \sin$ formación académica musical. Se pretende estudiar cómo estas prácticas favorecen un nuevo acercamiento a la creación musical y a la construcción cultural al margen de los marcos convencionales o institucionales y de qué manera estas interrelaciones suponen un nuevo marco de acción para la transformación social a través del arte.

\section{Materiales y Método}

La metodología de investigación utilizada ha sido la etnografía, por resultar coherente con las pretensiones y el objetivo de la investigación de carácter descriptivo-explicativo. Como señalan del Olmo y Osuna (2014), la etnografía investiga con personas y resulta apropiada cuando queremos comprenderlas y necesitamos ponernos en su lugar. Según Lincoln y Guba (1995), la observación naturalista puede proporcionar abundante información sobre la vida de las personas, sus relaciones e interacciones sociales, las tensiones ocultas, las herramientas que utilizan y el ambiente que habitan. En este sentido, nos permite analizar "la acción social, el orden social y la organización social, así como analizar las formas y los contenidos de la cultura" (Atkinson y Delamont 2012, p. 394).

La muestra de participantes estaba conformada por 13 creadores musicales sin formación académica en música, ubicados entre las ciudades de Valencia y Castellón y que interactuaban desde los contextos informales de forma individual y colaborativa, conformando nodos y redes de creadores en territorios offline y online. Se priorizó así su condición de no músicos, patrón de coincidencia relevante y coherente con las finalidades del estudio.

Todos los participantes, además, abordaban la música desde estilos experimentales mediados por la tecnología y combinaban la creación individual y colaborativa con diversidad de estilos musicales, generando nuevos espacios de creación sonora. En la investigación se tuvo en cuenta cuáles eran las tecnologías y contextos que mediatizaban sus interacciones para entender cómo nuestros participantes hacían uso de todo ello y aprendían y colaboraban para producir sus creaciones.

Los instrumentos de recogida de información utilizados fueron: las entrevistas individuales y grupales semiestructuradas, así como la técnica de observación participante que permitieron generar un "proceso de investigación inductiva" (Angrosino, 2012, p. 82) durante los seis meses que duró el trabajo de campo.

Así mismo, y de forma resumida, se realizaron registros sonoros y audiovisuales de conciertos, ensayos y reuniones, coincidiendo con un ciclo de conciertos dentro del festival Off_Herzios, autogestionado por algunos de los participantes. Además, se hizo uso del cuaderno de campo y se recurrió al análisis documental de diversas plataformas de tipo netlabel, junto a la observación y participación en foros, a través de Facebook, con todos los participantes de la muestra seleccionada.

Una vez transcrita la información textual y audiovisual recogida en el trabajo de campo, se procedió a hacer un volcado al software Atlas-ti para organizar la información en diferentes unidades hermenéuticas.

En primer lugar, se realizó una codificación abierta para detectar unidades significativas dentro de los datos recogidos. En una fase posterior se procedió a una codificación axial con la finalidad de depurar y diferenciar las categorías derivadas de la codificación abierta. A partir de las numerosas categorías que se originaron, se seleccionaron las que parecían más prometedoras para una elaboración adicional, en función de su capacidad de saturación y/o del potencial explicativo que albergaban en relación a las preguntas de investigación (Massot, Dorio, y Sabariego, 2009).). Esta categorización axial se enriqueció por ajuste con el mayor número de pasajes posible. Las relaciones desarrolladas y las categorías que se tratan como esenciales se verificaron una y otra vez frente el texto y el resto de datos.

Por último, dentro de este proceso, se llegó a la codificación selectiva con el propósito de elaborar una categoría central alrededor de la cual otras categorías desarrolladas se pudieran agrupar e integrar, dando como resultado un tipo de relato denso. Finalmente, y para realizar la validación de las categorías y ofrecer un mayor rigor en la construcción del relato etnográfico, se ha seguido el criterio de credibilidad de la investigación cualitativa, utilizando la observación persistente, la comprobación con los participantes y la triangulación de los datos (Dorio, et al; Guba,

\footnotetext{
Se adopta a lo largo del estudio el término acuñado por Brian Eno en los años 70 para referirse, con cierta ironía y provocación ante posturas aca-
} demicistas, a los músicos sin formación musical reglada. https://blog.oup.com/2014/05/brian-eno-influential-non-musician/ 
1985). En el proceso de triangulación, en primer lugar se ha realizado una triangulación de la información dentro del colectivo estudiado, entre las personas participantes en el estudio; y posteriormente se ha realizado una triangulación entre los diversos instrumentos de recogida de información (Cisterna, 2005).

Así mismo, por cuestiones éticas adoptadas en la investigación, se decidió ocultar los nombres de los participantes en los resultados. Para ello se utilizan los códigos: EI, Entrevista Individual; NCI, Notas de Campo Investigador; EG, Entrevista Grupal; OP, Observación Participante, acompañados de un número que identifica al participante; AD, Análisis Documental.

\section{Resultados}

\subsection{Ver y escuchar la música: la liberación del creador a través de la revolución tecnológica}

Las herramientas que proporcionan las tecnologías facilitan a los creadores el acceso al sonido de una forma quirúrgica, así pueden diseccionar, alargar, cortar, fusionar... en el interior del sonido y transformarlo o adaptarlo a sus necesidades. Esta manera de acercarse a la creación sonora rompe con ortodoxias que encontramos desde la formación académica, donde necesariamente se tiene que pasar por la lectura musical. Debido a ello, los "no músicos" desarrollan otras estrategias, donde la tecnología, a través de la experimentación sonora, hace una función mediadora entre las ideas y la música. En este sentido, hay que resaltar que, para ellos, el uso de la tecnología musical refuerza la idea de antitécnica y permite crear música sin la necesidad de dominar técnicamente un instrumento musical convencional, por lo que no se consideran intérpretes sino creadores. Las herramientas informáticas les proporcionan recursos creativos que compensan significativamente las limitaciones técnicas. Para ellos lo importante no consiste en convertirse en intérpretes virtuosos, sino que su prioridad es la investigación mediante la construcción de un sonido distintivo y personal.

Para los participantes seleccionados, al no utilizar partituras convencionales, el acceso a la creación sonora está totalmente guiado por la escucha ante el acto sonoro, por la manipulación constante del objeto especulativo: el sonido. Pero hay que resaltar que en algunos casos hay un estímulo visual producido por la forma de onda a través de la pantalla del ordenador que funciona como una "marca visual" para el creador. De este modo, el creador amplía su repertorio sensorial sonoro y visual.

[...] La tecnología nos ha permitido visualizar el sonido; además de escucharlo, ahora puedes manipularlo de una forma muy plástica [...] EI-1

En la mayoría de los casos, los participantes de la investigación utilizan las diferentes herramientas digitales aplicadas a la creación musical como ampliación de la paleta sonora, ya que las posibilidades de remezcla son infinitas. Frente a otros tipos de instrumentistas, su interacción constante y el fuerte componente de experimentación digital marcan su singularidad, que apuesta por incrementar su imaginario sonoro y proporcionar un feedback constante de ideas para completar y mejorar sus creaciones.

Ellos, con sus formas de hacer música, apuestan por una ruptura del concepto de sacralización que envuelve el acto de creación en la cultura musical académica. Si hace unos años la creación sonora estaba prácticamente ligada a los estudios reglados de composición, actualmente las tecnologías digitales refuerzan la idea que todo el mundo tiene la posibilidad de ser creador. Así pues, podemos hablar de una democratización del acto de creación musical ocasionado por el uso de este tipo de tecnologías: no hace falta una formación musical especializada para componer música.

[...] En cierto modo, se ha desacralizado mucho al creador. Hoy cualquier persona con un software mínimamente decente puede tener un estudio en su ordenador y crear su propia música [...] EI-2

Desde esta visión, se alejan de la tecnología como "sustitución" apostando por una tecnología de verdadera transformación. Un uso de la tecnología que los acerca hacia otros territorios sonoros, fruto de la experimentación, con resultados muy personales y creativos.

[...] Después fui abandonando esa idea de fidelidad de aquello que toco en beneficio de la manipulación sonora para hacer aquello que "necesito" hacer: coger lo que necesito, manipularlo y transformarlo por unas necesidades concretas, sin ningún dogma ni filosofía detrás [...] EI-3

El uso de las herramientas digitales les aportan un alto grado de autonomía, generando espacios de creación en su propio contexto doméstico. Esta posibilidad ofrece un alto grado de libertad al no músico, el cual dispondrá de un laboratorio a su alcance para crear la música, rompiendo con la dependencia del estudio de grabación profesional y las reglas de juego impuestas por la industria. 
[...] La disponibilidad de nuevos recursos digitales y el control del tiempo personal, potenciado por la proximidad de las herramientas, crea unas nuevas condiciones en el acceso a la creación sonora [...] NCI

[...] Empezar en solitario, sin estar sujeto a unas formas determinadas. Vi que había una música que no necesitaba de reglas estrictas, que tenía más libertad. No era aquello de hacer lo que te da la gana, pero era un paso hacia una mayor libertad. Bajo tu responsabilidad, teniendo siempre claro que no puedes engañar a nadie, ni engañarte tú mismo [..] EI-2

Los usos diversos de la tecnología y la hibridación continua de lenguajes les permite explorar nuevos lenguajes artísticos. La interacción entre la imagen y el sonido, la danza, el dominio y transformación del espacio escénico potencian la confluencia de diferentes lenguajes artísticos. De esta manera, refuerzan una visión de artes integradas, redescubriendo nuevos territorios donde destaca de forma significativa, el enriquecedor diálogo entre creadores de diferentes disciplinas.

[...] En esta propuesta-acción iba pintando un cuadro y después iba interpretándolo con la batería. Empezaba haciendo una asociación con la teoría de los colores de Kandinsky, los amarillos con frecuencias más agudas, después los colores más fríos con los más graves, los rojos con los tambores... es decir, iba asociando los colores con diferentes instrumentos hasta que el cuadro quedaba completamente negro y hacía un ambiente muy ruidista [...] EI-4

\subsection{El estudio doméstico como espacio de creación}

La revolución digital les permite hacer uso de unas tecnologías que hasta hace poco habían sido de acceso exclusivo a través de los grandes estudios de grabación. Su abaratamiento y miniaturización, entre otras ventajas, permiten a los participantes de esta investigación el uso de un sinfín de artefactos y software que facilitan la democratización de la creación musical desde sus propias casas.

[...] la tecnología es ahora mucho más barata. Una cosa que siempre había pensado era que, si me tocara la lotería, me compraría un estudio de 50 millones, pero la tecnología había cambiado y por primera vez tenía la posibilidad de tener un estudio sin salir de casa [ .... EI 2

Su inventario de herramientas digitales y artefactos es tan diverso como sus formas particulares de hacer música. No encontramos una predilección por unos artilugios o software concretos. Su curiosidad por explorar e investigar, sobre todo lo relacionado con la manipulación sonora, les sitúa en una relación de betatesters a tiempo completo así, como luthiers de sus propios instrumentos. Este tipo de prácticas experimentales les proporciona una nueva relación con el universo sonoro y la interacción con los objetos sonoros y su contexto sonoro: la ciudad y sus espacios les permite ampliar su paleta sonora a través de una manipulación constante de los parámetros constitutivos del sonido.

Dependiendo de su disponibilidad económica mantienen una actualización constante en cuanto a la última tecnología que sale al mercado y su necesidad de exploración sonora les empuja a mantener una actitud de investigación permanente.

Este planteamiento del uso de la tecnología les permite adoptar un posicionamiento altamente creativo en el uso de todos los dispositivos que tienen a su alcance, superando el límite de su funcionalidad y situándolos en un proceso de descubrimiento continuo y sumamente disruptivo.

[...] La exploración creativa que aplico en los aparatos que utilizo me permite superar sus limitaciones, cambiando a veces las funciones para las cuales están hechos o programados [...] EI-5

\subsection{Compartir y construir desde las redes sociales: tecnología al servicio de la comunicación}

Para los no músicos del estudio, las tecnologías digitales desplegadas a través de internet les han afectado significativamente, permitiendo introducir en su trabajo elementos que conforman una nueva geografía de las relaciones humanas y definen nuevas fórmulas de colaboración y negocio musical.

[...] A mí la tecnología que más me ha afectado realmente ha sido internet, no solo a nivel musical, sino más bien a nivel cultural. Pienso que esto mismo es generacional, nadie de 20 o 30 años te puede negar que más de la mitad de la cultura que tiene está extraída de internet. La otra parte será seguramente por la escuela, la familia, las relaciones sociales, motivaciones personales... pero el resto es internet [...] EG

La red social más empleada por el grupo es Facebook, todo el grupo investigado comparte la información con el resto a través de las redes sociales. Es habitual compartir cualquier acontecimiento en el que participa alguno de los miembros y de este modo mantenerse informados. 
[...] Dentro de la diversa tipología de post podemos encontrar los de cariz informativo, donde se anuncian conciertos, nuevos trabajos, grabaciones de vídeos. Y otros, de cariz crítico, donde a través de un artículo de interés, noticias de revistas especializadas, artículos de opinión de periódicos o enlaces a entrevistas de radio y televisión, provocan la participación y la reflexión alrededor de un tema de interés común[...] AD (del muro del Facebook)

[...] sobre todo en el Facebook donde compartimos mucha información. En el tiempo de la Clínica Mundana, si no hubiera sido por el Facebook, la cosa habría sido diferente. Igual hay gente que me puede contradecir pero a mí me parece que el Facebook ha unido a mucha gente, aquí en España, o en nuestro microcosmos [...] EI 6

Además de esta red social, el grupo utiliza otras plataformas para difundir y compartir sus trabajos. Casi todo el grupo tiene trabajos o producciones sonoras en netlabels nacionales o internacionales. Estas plataformas cumplen diferentes finalidades. Por una parte suponen una oportunidad para dar a conocer y compartir su trabajo con aquella comunidad interesada en este tipo de músicas y también facilitan que se hagan visibles ante usuarios interesados, creando verdaderas bibliotecas sonoras online de libre acceso. Por otra parte, desplazan el concepto de negocio musical hacia otras fórmulas donde la venta física o por descarga quedan prácticamente anuladas.

El nuevo planteamiento del negocio musical no se hará por la venta del producto ni en físico ni en descarga, será más bien por el concierto en directo o por una diversidad de propuestas como pueden ser talleres, seminarios, festivales... que son producto de la difusión del trabajo del creador mediante estos nuevos canales de difusión y distribución.

[...] Yo seguía anclado a los viejos sistemas. Pensaba que si hacía algo que tuviera cierta calidad, alguien vendría a buscarme, pero las cosas ya no funcionaban así. Un día recibí un email desde Italia donde me preguntaban si tenía algo editado y dije que no, porque ningún netlabel me había ofrecido nada. Aquella persona me dijo: no te preocupes, yo te hago una netlabel solamente para que tú publiques. Poco a poco iba creándose una red [...] EI 2

Es habitual el uso de plataformas de tipo Bandcamp que, junto a la opción que ofrecen las netlabel, constituyen uno de los espacios virtuales más empleados por casi la totalidad de los participantes del estudio. Esta plataforma permite al artista la autogestión de su propio producto y da la opción de monetizar su obra a través del pago por descarga o continuar con la opción de descarga gratuita ofertada por las diversas netlabel que coexisten en la red.

Los cambios más significativos que observamos respecto al uso de estas nuevas plataformas son la autogestión del artista, eliminando intermediarios, el control absoluto de producto artístico por parte del músico, la democratización y universalización de la cultura a través de una libre distribución del conocimiento. De este modo el conocimiento cultural es distribuido horizontalmente, eliminando la polarización de las grandes compañías discográficas y conformando, con este tipo de plataformas, auténticos nodos de información y colaboración enlazados a través de la red.

\section{Discusiones y conclusiones}

Es innegable la repercusión de las tecnologías digitales en las formas de hacer música. En la mayoría de los casos estudiados, el acceso a la tecnología ha facilitado la creación musical y su uso ha aportado evidencias enriquecedoras que, sin caer en la complacencia fácil de una idea casi mágica de la tecnología, puede superar una posición de rechazo a estas.

En el panorama de las artes se hace cada vez más evidente el papel de cómo la incorporación y uso de nuevas metodologías y herramientas digitales aportan una ampliación tanto de la práctica artística como de la redefinición del papel y respuesta de los artistas e instituciones generando nuevos ecosistemas creativos.

En los procesos de creación observados en este estudio, los participantes se convierten en auténticos alquimistas sonoros. Los avances en la tecnología digital permiten congelar y esculpir el sonido propiciando una diversificación en las maneras de escuchar, crear y producir música. La tecnología les introduce en el interior mismo del sonido. Esta novedad les ofrece la capacidad de trabajar el sonido de una forma que acentúa la relación física con éste y les facilita construirlo y deconstruirlo de formas antes impensables, convirtiéndoles en auténticos "escultores" del sonido (Márquez, 2010). La plasticidad en las maneras de hacer refuerza la actitud experimental y acentúa los procesos creativos, puesto que ofrece una manipulación directa del acontecimiento sonoro con formas muy originales y personales que han incidido en la transformación de la cultura musical (Serra, 2008). Como afirma Delalande (2008), la revolución tecnológica determina una nueva orientación estética que abandona las combinaciones entre horizontal y vertical en pro de una investigación del sonido y una reestructuración de las prácticas sociales.

La utilización de la tecnología les ha facilitado otras técnicas creativas. Los diferentes softwares aportan recursos suficientes y convierten los artefactos utilizados en recursos que permiten avanzar en la creación sonora teniendo algunas nociones teóricas o habilidades instrumentales básicas (Folkestad, 2012). Como señala Giráldez (2010), la composición musical ya no puede considerarse una ocupación reservada sólo a los especialistas, sino una actividad que puede ser desarrollada por cualquier persona con la motivación y el interés necesario.

A lo largo de la investigación hemos visto que la notación musical es superada por la irrupción de la tecnología en la creación sonora; superan la notación, pues ya no atienden a la nota y a la disposición en el pentagrama. Los nuevos creadores atienden al sonido como materia prima. Gracias a la tecnología virtual de estudio, es posible dibujar 
la música en la pantalla del ordenador como una onda representada visualmente: el sonido puede editarse y recombinarse hasta el infinito, ordenado y sujeto a todo tipo de tratamientos y efectos, según Reynolds, (2006, pp.18-19) “El pigmento es más importante que el trazo".

Debido a estos cambios, que se configuran como un proceso democratizador, existe hoy en día una cultura de músicos, creadores, artistas sonoros, investigadores y oyentes que prestan atención al material sonoro, al hecho de la escucha y a las posibilidades creativas de la grabación, reproducción y transmisión del sonido (Cox y Warner, 2004).

Su visión de la cultura prototípica los lleva al rechazo a la rutina, fortalecida por una actitud de cambio constante que permite el flujo dinámico de nuevas propuestas generadoras de conocimiento. Son una muestra de la potencialidad de la inteligencia colectiva y, en su caso, emplean la música como catalizador de nuevos proyectos que van mucho más allá de las propuestas locales y tienen la capacidad de producir fricciones y nuevas conexiones entre diferentes nodos. Si las formas de hacer música se diversifican, también lo hacen los espacios donde acaban introduciéndose para provocar transformaciones y rupturas.

Un espacio con gran capacidad de transformación y ruptura será sin duda el estudio de grabación doméstico. Esta “domesticación” de las herramientas digitales, según Théberge (1997, P.234), puede ser comparable a la incorporación del piano al ámbito doméstico y su repercusión en la producción y difusión social de la música que permitió ir más allá de la sala de conciertos. Y de la misma manera, también se diversifican los recursos que utilizan. El reciclaje se hace presente en muchas de sus opciones creativas, convirtiéndolos en creadores-luthiers que construyen sus propios instrumentos partiendo de artefactos y otros materiales, encajando perfectamente en la filosofía del Do it yourself (DIY).

En sus actitudes es visible el interés por una nueva sensibilización del arte sonoro, sensibilización dada por la diversidad de estilos y estéticas que con toda naturalidad crecen y se hibridan las unas con las otras. Su actitud emprendedora los empuja a reinventarse en cada acción que comienzan. La heterogeneidad, la mezcla de estilos y las formas de encajarlos nos hablan de otras formas más diversificadas, democráticas y dialógicas de crecer en la diversidad y desde la adversidad. El carácter diverso los hace más fuertes, potencia y aumenta la colaboración haciéndolos más permeables, borrando las fronteras entre las disciplinas artísticas y ganando nuevos sectores de audiencia procedente de una franja social que, aparentemente, no estaba interesada en las propuestas oficiales.

El nuevo paradigma desdibuja la frontera entre el amateur y el profesional, volviendo indistintos los límites que separaba el rol del autor musical del oyente, o del músico aficionado y el profesional (Ahonen, 2004). Algunas de las razones por las cuales se difuminan paulatinamente son las posibilidades que las tecnologías digitales musicales ofrecen al público en general. La tecnología actúa como mediadora entre las ideas y la producción sonora y su uso aporta una visión que supera la máquina para transportar la creación sonora a nuevos territorios y formas de hacer sin renunciar al pensamiento humano, superior a los encantos de las máquinas. La familiaridad práctica también los acerca a un uso multidisciplinario donde confluyen diferentes lenguajes artísticos que permiten constantes hibridaciones entre los diferentes códigos expresivos deliberadamente mezclados. Las combinaciones resultantes se acercan a un concepto de remix (Lessig, 2008) que no sólo afecta al mundo de los sonidos, sino que se ensancha a través de la integración y fusión de varias narrativas artísticas. La música se refuerza con las aportaciones procedentes de diferentes campos artísticos y refuerza el concepto de creador multidisciplinar que domina y usa diferentes softwares de audio y vídeo. Esta polivalencia es posible en parte por un cambio en el perfil del creador que necesita el dominio en diferentes campos para crear productos más originales y diversificar así su tarea. Cómo afirma Freire (2006) el remix es una versión moderna de la colaboración.

Cuando la tecnología se desplaza al terreno virtual, nuestros participantes alcanzan los territorios de diferentes plataformas que configuran la relación entre los creadores y sus escuchas, generando formas inéditas de recepción y consumo musical. Contrario a la distópica visión que Internet sirve principalmente para aislar a la gente, Howe (2008) afirma que el crowdsourcing utiliza la tecnología para fomentar unos niveles de colaboración sin precedentes y unos intercambios significativos entre personas de cualquier contexto o localización geográfica imaginable. La diversificación de las herramientas que nuestros participantes usan, favorece nuevas fórmulas de distribución basadas en la autogestión y socavan las ya debilitadas formas con las cuales el mercado discográfico ha persistido. En el caso de las netlabels o plataformas Bandcamp, la distribución gratuita de sus producciones provoca un poderoso efecto de difusión entre un público prosumidor (Toffler, 2004; Tapscott, 1995) que se convierte a través de las redes sociales en un potencial nicho informativo, compartiendo sus experiencias y descubrimientos musicales. Estas mismas herramientas permitirán a los creadores generar una cantidad ingente de relaciones virtuales y personales. Su presencia en las redes sociales estimula la construcción de nuevas audiencias y de nuevos vínculos laborales a través de las colaboraciones derivadas y las autorías colectivas.

A lo largo de la investigación podemos evidenciar nuevas formas de hacer y vivir la música. Por lo tanto, aquello que hemos observado y estudiado supera la visión de unas estructuras que, ya en descomposición, no encajan con las necesidades ni demandas de la sociedad contemporánea del s. XXI.

Unas estructuras que han favorecido y priorizado -al amparo de la subvención- unas formas culturales programadas "desde el despacho", provocando la pervivencia de unas estructuras rígidas y jerárquicas que han negado la presencia de las otras músicas y de muchísimas propuestas culturales contemporáneas que ponen de manifiesto otras formas de hacer música (Galiana, 2012, 2019). Nuevos modelos organizativos que evidencian una horizontalidad 
en sus formas internas de relacionarse y que rizomáticamente alcanzan territorios que, a pesar de su invisibilidad, conforman el magma de un capital cultural que revitaliza barrios y ciudades y crea nuevos espacios. La complejidad de sus entramados, basados en una colectividad creativa, ha resultado difícil de medir y detectar por la pesada maquinaria administrativa que, alineada con otros modelos organizativos, parece ciega ante este tipo de manifestaciones emergentes.

La música, más allá de una profesión -que también lo es- nos muestra en su hacer habitual otras posibilidades: el arte al alcance de todo el mundo es una experiencia que enriquece y aporta reflexiones y creatividad a cada acto cotidiano (Ferrando, 2013). Las formas de hacer y vivir las experiencias sonoras de los no músicos, legítimas como cualquier acto de expresión artística, aportan nuevos elementos que ayudan a configurar nuevas cartografías culturales que enriquecen la creación y aprovechamiento de otros espacios, reorientan hacia otras políticas culturales que se vertebran desde abajo, generando nuevas actitudes y posicionamientos ante formas de expresión más minoritarias, favoreciendo fórmulas inclusivas a partir de una multiplicidad de actores, independientemente de su condición sociocultural.

Sus prácticas, a día de hoy, representan el empoderamiento ciudadano prosumidor, que es partícipe de las propuestas y tiene la capacidad de tejer nuevas relaciones y formas distributivas de la cultura, aportando una fuente refrescante de innovación social muy importante y necesaria.

Poner la mirada en este tipo de colectivos aporta nuevas soluciones que permiten fortalecer el tejido social y cultural de nuestra sociedad a través de una cultura más participativa.

\section{Referencias Bibliográficas}

Ahonen, L. (2004). Mediated music makers. Constructing author images in popular music. Helsinki: Finnish Society of Ethnomusicology.

Angrosino, M. (2012). Etnografía y observación participante en investigación cualitativa. Madrid: Morata.

Atkinson, P. y Delamont, S. (2012). Perspectivas analíticas. En N.K. Denzin e Y.S. Lincoln (coords.). Manual de investigación cualitativa. Vol. IV. Métodos de recolección y análisis de datos, (pp. 369 - 408). Barcelona: Gedisa.

Barber, Ll. y Palacios, M. (2009). La mosca tras la Oreja: de la música experimental al arte sonoro en España. Madrid: Fundación autor SGAE.

Cisterna, F. (2005). Categorización y triangulación como procesos de validación del conocimiento en investigación cualitativa. Theoria, 14(1), pp. $61-71$.

Cobo, R. C. y Pardo, K. H. (2007). Planeta web 2.0: Inteligencia collectiva o medios fast food. Grup de Recerca d'Interaccions Digitals. Barcelona / México DF.: Universitat de Vic. Flacso México.

Cobo R, C. y Moravec, J, W. (2011). Aprendizaje Invisible. Hacia una nueva ecología de la educación. Col·lecció Transmedia XXI. Laboratori de Mitjans Interactius.Barcelona: Publicacions i Edicions de la Universitat de Barcelona.

Cobo, R, C. (2016). La Innovación Pendiente. Reflexiones (y Provocaciones) sobre educación, tecnología y conocimiento. Montevideo: Colección Fundación Ceibal/ Debate..

Cox, C. y Warner, D. (2004). Audio Culture: Reading in Modern Music. New York: Continum

Del Olmo, M. y Osuna, C. (2014). Introducción a la investigación etnográfica. En B. Ballesteros. Taller de investigación cualitativa (pp. 48 - 76). Madrid: Universidad Nacional de Educación a Distancia.

Delalande, F. (2004). La enseñanza de la música en la era de las nuevas tecnologías. Comunicar, 23, 17-23. doi.org/10.3916/ C23-2004-04

Delalande, F.(2008). Un millón de compositores. En A. Giráldez (Coord.), Percepción y expresión en la cultura musical básica (pp. 7-17). Madrid: Ministerio de Educación, Política Social y Deporte.

Dorio, I.; Sabariego, M. y Massot, I. (2009). Características generales de la metodología cualitativa. En R. Bisquerra (Coord.), Metodología de la investigación educativa (pp. 275 - 292). Madrid: La Muralla.

Eco, U. (2001). Apocalipticos e integrados. Barcelona: Lumen y Tusquets.

Feichas, H. (2010). Bridging the gap: Informal learning practices as a pedagogy of integration. British Journal of Music Education 27, 47-58. doi.org/10.1017/S0265051709990192

Ferrando, B. (2013). Arte y cotidianidad. Hacia la transformación de la vida en arte. Madrid: Ardora.

Folkestad, G. (2012). Digital tools and discourse in music: The ecology of composition. En D. Hargreaves, D. Miell y R. MacDonald (Eds.), Musical imaginations: Multidisciplinary perspectives on creativity, performance and perception. New York: Oxford University Press.

Freire, J. (2010).“Cultura digital y prácticas creativas en educación. Revista de Universidad y Sociedad del conocimiento 6(I), 2-5. Barcelona: UOC.

Freire, M. J. (2006). Como una autopista: encuentros de electrónica y música popular, En Blánquez, J. I Morera, O. (Coord) Loops: una historia de la música electrònica. (pp. 473-507) Barcelona: Reservoir Books.

Galiana G, J.L. (2012). Valencia improvisa libremente. En VV. AA.: Congreso 100 Años de Arte Sonoro Valenciano o la Valencia de la Modernidad Trabada. Valencia: UPV.

Galiana G, J.L. (2019). De las músicas experimentales valencianas y otras turbulencias sonoras durante la crisis (2008-2018). En Calle, Romà de la, (Coord) Los últimos diez años del arte valenciano contemporáneo (2008-2018). Entre la crisis, la 
resistencia y la imaginación. Col·lecció Investigació \& Documents, Volumen 26. Valencia: Real Academia de Bellas Artes de San Carlos.

Giráldez, A. (2010). La composición musical como construcción: Herramientas para la creación y la difusión musical en internet. Revista Iberoamericana de educación, 52, 109-125. Consulta en línea: http://www.rieoei.org/rie52ao6.pdf

Guba, E. G. (1985). Criterios de credibilidad en la investigación naturalista. En J. Gimeno y A. Pérez (Comps). La enseñanza: su teoría y su práctica (pp. 148 - 165). Madrid: Akal.

Green, L. (2008). Music, informal learning and the School: A new classroom pedagogy. Aldershot, UK: Ashgate.

Himanen, P. (2001). La ética del hacker y el espiritu de la era de la información. Barcelona: Destino.

Howe, D. (2008). The Emotionally Intelligent Social Worker Basingstoke.Plagrave Macmillan. doi.org/10.1177/1468017309359891

Lessig, L. (2008). Remix. Making Art and Commerce Thrive in the Hybrid Economy. Londres: Bloomsbury.

Lévy, P. (2004). Inteligencia colectiva: por una antropología del ciberespacio. En línea: http://inteligenciacolectiva.bvsalud .org

Lévy, P. (2007). Cibercultura: La cultura de la sociedad digital. Barcelona: Anthropos.

Lincoln, Y. S. y Guba E. G. (1995). Naturalistic Inquiry. Londres: Sage.

Márquez, V. I. (2010). "Hipermúsica: la música en la era digital”. Trans. Revista transcultural de música, 14, 1-8. Madrid: Sociedad de Etnomusicología.

Massot, I., Dorio, I. y Sabariego, M. (2009). Estrategias de recogida y análisis de la información. En R. Bisquerra (Coord.), Metodología de la investigación educativa (pp. 329 - 366). Madrid: La Muralla.

Melero, D. (2012). Orgullo de no músico Diario digital la Nueva. Consulta en línea: http://www.lanueva.com/weblogs/blogciudad291/comentarios/cf3ae5814c/239/123068.html

O'Flynn, J. (2006). Vernacular music-making and education. International Journal of Music Education 24(2): $140-47$. doi: $10.1177 / 0255761406065475$

Olmo, M. y Osuna C. (2014). ¿Qué tiene que decir la Etnografía sobre el abandono escolar? Contextos multiples de socialización y aprendizaje: un análisis desde la etnografía de la educación: [II congreso Internacional de Etnografía y Educación: Madrid. Traficantes de Sueños.

Pardo, C. (2014). La escucha oblicua: una invitación a John Cage. Madrid: Sexto Piso.

Reynolds, S. (2006). Prefacio En Blánquez, J. I Morera, O. (Coord) Loops: una historia de la música electrónica. (pp.15-37) Barcelona: Reservoir Books.

Rostwall, A, L. y S. Selander. (2008). Design för lärande [Design for learning]. Stockholm: Norstedts Akademiska Förlag.

Sátiro, A. (2010). "Pedagogía creativa desde la condición humana" en Aula de Innovación Educativa, 193, 9-15. Barcelona: Graó.

Serra, X. (2008). De la Cultura Musical a la Cultura del So en la Societat Tecnològica. 2 n Congrés Internacional de Música. Barcelona: Universitat Pompeu Fabra.

Sevillano, J. (2000). Ultra_minimal_digital ¿La música electrónica del s. XXI? En línea: http://www.ccapitalia.net/reso/articulos/ minimal/minimall.htm

Tapscoot, D. (1995). The digital economy. London: McGrawGill.

Théberge P. (1997). Any Sound You Can Imagine: Making Music/Consuming Technology. London: Wesleyan University Press.

Toffler, A. (2004). La tercera ola. Madrid: Plaza \& Janes. 